\title{
EFFECT OF DIFFERENT RECOVERY MODALITIES ON REPEATED-SPRINT PERFORMANCE IN AMATEUR SOCCER PLAYERS
}

original paper

doi: https://doi.org/10.5114/hm.2017.73620

\section{JURAJ PECHO ${ }^{1}$, LUBOSLAV ŠIŠKA ${ }^{2}$, ADAM ŠČIBRÁNY ${ }^{3}$, ERIKA ZEMKOVÁ ${ }^{1}$}

${ }^{1}$ Department of Sports Kinanthropology, Faculty of Physical Education and Sports, Comenius University in Bratislava, Bratislava, Slovakia

${ }^{2}$ Department of Physical Education and Sport, Faculty of Education, Constantine the Philosopher University in Nitra, Nitra, Slovakia

${ }^{3}$ Department of Track and Field, Faculty of Physical Education and Sports, Comenius University in Bratislava, Bratislava, Slovakia

\section{ABSTRACT}

Purpose. The study evaluates the effect of low-frequency electrical stimulation (LFES) of calf muscles on repeated-sprint performance and compares it with the frequently used active (ACT) and passive (PAS) recovery in amateur soccer players. Methods. A group of 11 amateur male soccer players completed 2 repeated-sprint ability (RSA) tests $(7 \times 34.2 \mathrm{~m}$ with $25 \mathrm{~s}$ of ACT recovery between sprints) separated by a 15-min recovery period. During recovery, 1 of the 3 recovery modalities (PAS, ACT, or LFES) was randomly selected.

Results. Mean sprint time significantly increased between the first and the second RSA test after PAS (from $6.43 \pm 0.21 \mathrm{~s}$ to $6.49 \pm 0.23 \mathrm{~s} ; p=0.029$ ) and LFES (from $6.45 \pm 0.25 \mathrm{~s}$ to $6.54 \pm 0.27 \mathrm{~s} ; p=0.025$ ), whereas its values did not change significantly after ACT (from $6.42 \pm 0.21 \mathrm{~s}$ to $6.45 \pm 0.2 \mathrm{~s} ; p=0.093$ ). However, small effect sizes indicate that the changes in mean sprint time after these 3 recovery modalities were not practically significant (PAS, $d=0.22$; LFES, $d=0.29$; ACT, $d=0.13)$. In addition, mean sprint time in the RSA test did not differ significantly between groups that underwent different recovery modalities.

Conclusions. These findings indicate that practitioners can use any of these different recovery modalities, basing on their desire. Key words: passive recovery, active recovery, low-frequency electrical stimulation, repeated-sprint ability test

\section{INTRODUCTION}

Rapid recovery is very important for professional athletes playing intermittent sports, in which intense exercise periods are interspersed with short recovery periods. Active (ACT) and passive (PAS) are two commonly used recovery modalities. Several studies showed that ACT recovery had a better effect on performance than PAS recovery in different types of exercise [1-11].

Recent studies suggest that ACT recovery may be reproduced by low-frequency electrical stimulation (LFES) $[12,13]$. One of the examples is stimulation of calf muscles with Veinoplus Sport (Ad Rem Technology, Paris, France). Bieuzen et al. [12] found better 30 -second all-out rowing performances at 1 hour after intermittent fatigue exercise after LFES by Veinoplus Sport in comparison with PAS recovery in professional male soccer players $(p=0.03)$. However, no differences were observed in variables reflecting explosive strength. In another study by Bieuzen et al. [13], highly trained female handball players completed two Yo-Yo Intermittent Recovery level 2 tests (YYIR2) separated by a 15-min recovery period (randomly selected PAS, ACT, or LFES by Veinoplus Sport). LFES showed a very likely beneficial effect on performance during the second YYIR2 relative to PAS and a possible beneficial effect relative to ACT recovery (distance, pre vs. post: LFES, $-1.8 \%$; ACT, $-7.6 \%$; PAS, $-15.9 \%$ ). In a study by Borne et al. [14], elite male kayakers had the second 1000 -m kayak time trial very likely faster after $30 \mathrm{~min}$

Correspondence address: Juraj Pecho, Department of Sports Kinanthropology, Faculty of Physical Education and Sports, Comenius University in Bratislava, Nábr. arm. gen. L. Svobodu 9, 81469 Bratislava, Slovakia, e-mail: juraj.pecho@uniba.sk

Received: December 5, 2017

Acepted for publication: January 18, 2018

Citation: Pecho J, Šiška L, Ščibrány A, Zemková E. Effect of different recovery modalities on repeated-sprint performance in amateur soccer players. 2017;18(5)special/issue:77-82; doi: https://doi.org/10.5114/hm.2017.73620. 


\section{HUMAN MOVEMENT}

J. Pecho, L. Šiška, A. Ščibrány, E. Zemková, Recovery and repeated-sprint performance

of LFES with Veinoplus Sport combined with a cooling vest compared with ACT recovery combined with a cooling vest $\left(\mathrm{ACT}_{\mathrm{CR}}\right)(E S=1.6)$ and $\operatorname{LFES}(E S=0.6)$. The second time trial was also very likely faster after the LFES compared with $\mathrm{ACT}_{\mathrm{CR}}(E S=1.0)$.

However, the effect of 12-min LFES (which is applicable to the 15-min half-time period in soccer match) on repeated-sprint performance is unknown. The ability to perform repeated sprints and to be fast during a match is essential for soccer players, as the exercise pattern in a match frequently requires multiple sprints with limited rest periods [15]. Therefore, the aim of our study was to evaluate the effect of LFES of calf muscles by Veinoplus Sport on repeated-sprint performance compared with two other commonly used recovery modalities in amateur soccer players.

\section{MATERIAL AND METHODS}

\section{Participants}

The total of 11 amateur male soccer players $(19.5 \pm$ 1.2 years; $181.7 \pm 5.4 \mathrm{~cm} ; 74.1 \pm 9.0 \mathrm{~kg}$ ) volunteered to participate in the study. All of them were informed of the procedures and the main purpose of the study and provided their informed consent. The procedures presented were in accordance with the ethical standards on human experimentation stated in compliance with the Declaration of Helsinki.

Procedure

An overview of the experimental protocol is presented in Figure 1. Once a week at the same time of day, the athletes completed 2 repeated-sprint ability (RSA) tests interspaced by a 15-min recovery phase (corresponding to the half-time period in a soccer match). This phase consisted of 3 periods. In the first period, the players had $1.5 \mathrm{~min}$ after the first test to prepare for the second 12-min period, during which they used 1 of the 3 recovery modalities (ACT, PAS, or LFES). All participants performed all recovery modalities individually and in a randomized order. After that, they had 1.5 min to prepare for the second test. The training loads prior to and during the experiments were monitored. The players reported low intensity training between test sessions.

Repeated-sprint ability test

The protocol used for the RSA test was the same as that described by Bangsbo and Mohr [16]. The players

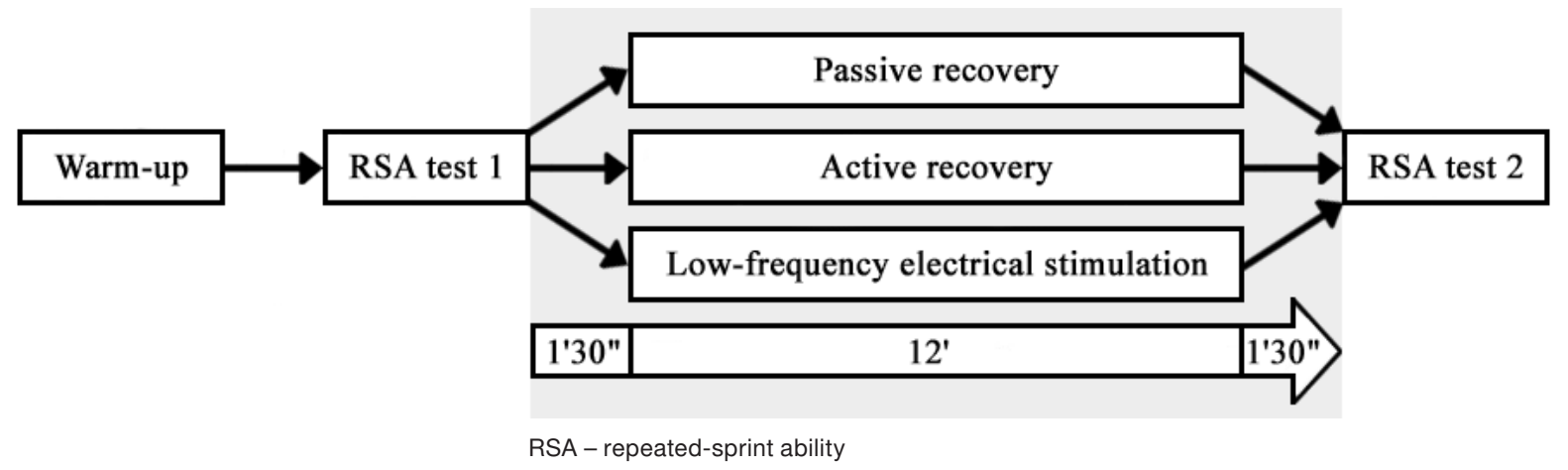

Figure 1. Experimental protocol

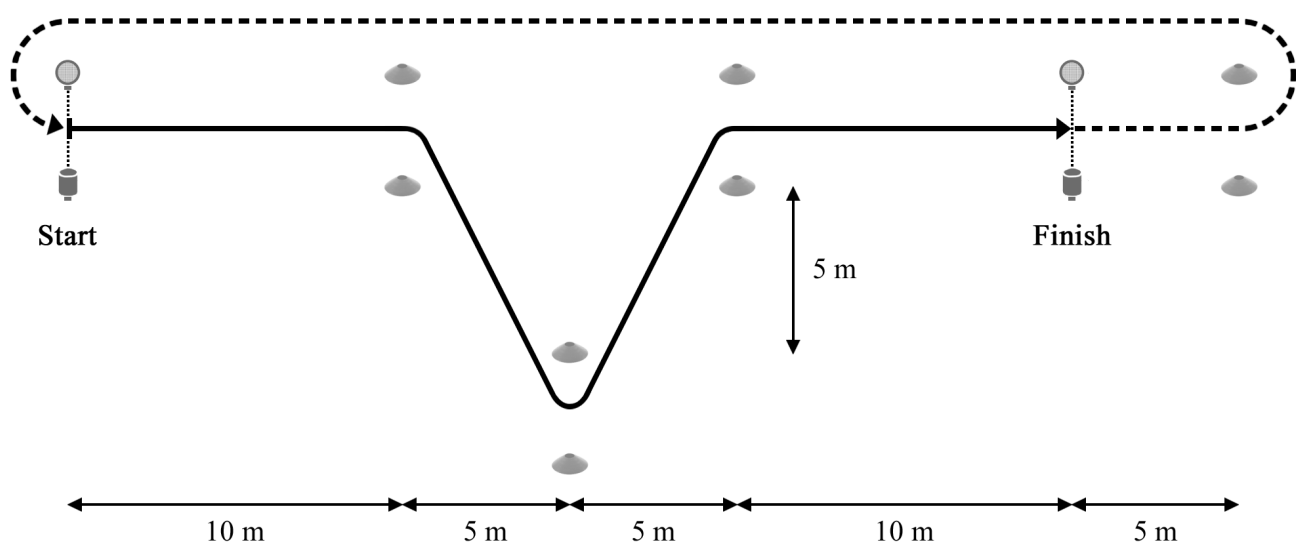

Figure 2. Test course of the repeated-sprint ability test 
performed 7 maximal 34.2-m sprints with change of direction separated by $25 \mathrm{~s}$ of ACT recovery that consisted of jogging, as shown in Figure 2. Photoelectric cells (FiTRO Light Gates, FiTRONiC, Slovakia) were applied to measure sprint times. Recovery time was controlled by a stopwatch, which allowed to ensure that the subjects returned to the initial point of course in $22 \mathrm{~s}$ to prepare for the next sprint. Also, a verbal feedback was given to the athletes at their 10, 20 and $25 \mathrm{~s}$ of the recovery. Performance was measured as the mean sprint time. The test was carried out indoors. Before the test, all participants completed a 15-min standardized warm-up protocol that consisted of $5 \mathrm{~min}$ of jogging at approximately $65 \%$ of maximal heart rate, followed by running drills and dynamic stretching, and finished with a task-specific high-intensity activity (linear and shuttle sprints).

\section{Recovery modalities}

The participants from the PAS and LFES groups remained seated on a bench throughout the 12-min recovery period. During this period, the individuals in the LFES group used the Veinoplus Sport electrical stimulator in the sitting position. The stimulation was applied via 2 skin electrodes $(8 \times 13 \mathrm{~cm})$ placed symmetrically on the medial-central part of the calf on both legs. The stimulation consisted of a series of rectangular pulses of low energy $(<25 \mu \mathrm{C})$, low voltage $\left(50 \mathrm{~V}_{\text {peak }}\right)$, with a carrier frequency of $250 \mathrm{~Hz}$ and impulse duration modulated from 25 to $250 \mu \mathrm{s}$. The device output is voltage controlled within the range of $0.5-50 \mathrm{~V}_{\text {peak }}$ in 100 steps of $0.5 \mathrm{~V}_{\text {peak }}$ each [13]. The voltage of stimulation was adjusted manually in the range of $17-50 \mathrm{~V}_{\text {peak }}$, depending on the player's tolerance. Each participant could adjust the output voltage on the basis of his tolerance. We set a minimal threshold corresponding to a visible contraction of the calf muscles. The ACT recovery consisted of a 12-min period of jogging or walking with heart rates in the range of 120-140 beeps per minute. The heart rate was measured by the Garmin Forerunner 610 device (Garmin Ltd., Olathe, Kansas, USA).

\section{Statistical analysis}

Data are reported as means $(M) \pm$ standard deviation $(S D)$. The normality of data sets was checked with the Shapiro-Wilk test. Differences in mean sprint time in the RSA test after 3 different recovery modalities were calculated by two-way ANOVA with repeated measures. The significance of differences of mean sprint time before and after the recovery phase was evaluated by t-test $(p<0.05)$. The practical significance of mean sprint time differences before and after the recovery phase was evaluated by the effect size. Effect sizes of $d \geq 0.2, d \geq 0.5$, and $d \geq 0.8$ were considered small, medium, and large, respectively [17]. Statistical analysis was performed with the use of the IBM SPSS Statistics software (SPSS Inc., Chicago, IL, USA).

\section{Ethical approval}

The research related to human use has been complied with all the relevant national regulations, institutional policies and in accordance the tenets of the Helsinki Declaration.

\section{RESULTS}

All of the data sets had a normal distribution of values. Performances of all groups with different recovery modalities in the RSA tests are presented in Table 1 . There were no significant differences in mean sprint time between the first and the second RSA test $\left(\mathrm{F}_{2,18}=4.0 ; p=0.316\right)$, with no differences between the recovery modalities $\left(\mathrm{F}_{2,18}=3.15 ; p=0.695\right)$ and no interaction between condition $\left(\mathrm{F}_{2,18}=0.315 ; p=0.932\right)$.

Mean sprint time significantly increased between the first and the second RSA test after both PAS (from $6.43 \pm 0.21 \mathrm{~s}$ to $6.49 \pm 0.23 \mathrm{~s} ; p=0.029$ ) and LFES (from $6.45 \pm 0.25 \mathrm{~s}$ to $6.54 \pm 0.27 \mathrm{~s} ; p=0.025$ ). However, the values did not change significantly after ACT (from $6.42 \pm 0.21 \mathrm{~s}$ to $6.45 \pm 0.2 \mathrm{~s} ; p=0.093$ ) (Table 2). Nevertheless, there were only small percentage changes which may be corroborated by small effect sizes after all 3 recovery modalities, i.e. PAS $(0.92 \% ; d=0.22)$, LFES $(0.47 \% ; d=0.29)$, and ACT $(1.38 \% ; d=0.13)$, respectively. These differences in sprint time between the first and the second RSA test

Table 1. Sprint time in the RSA test after different recovery modalities

\begin{tabular}{lcccc} 
& \multicolumn{2}{c}{$1^{\text {st }}$ RSA test } & \multicolumn{2}{c}{$2^{\text {nd }}$ RSA test } \\
Recovery & \multicolumn{2}{c}{ sprint time (s) } & \multicolumn{2}{c}{ sprint time (s) } \\
modality & Mean $\pm S D$ & $R$ & Mean $\pm S D$ & $R$ \\
& $6.43 \pm 0.14$ & 0.34 & $6.49 \pm 0.11$ & 0.27 \\
PAS & $6.42 \pm 0.14$ & 0.40 & $6.45 \pm 0.10$ & 0.25 \\
ACT & $6.45 \pm 0.12$ & 0.33 & $6.54 \pm 0.09$ & 0.26
\end{tabular}

PAS - passive recovery, ACT - active recovery,

LFES - low-frequency electrical stimulation,

RSA - repeated-sprint ability, $S D$ - standard deviation, $R$ - range 
J. Pecho, L. Šiška, A. Ščibrány, E. Zemková, Recovery and repeated-sprint performance

Table 2. Differences between the sprint time in the first and the second RSA test

\begin{tabular}{|c|c|c|c|c|c|c|c|}
\hline Recovery modality & Dif & $\begin{array}{c}\text { Standard } \\
\text { error mean }\end{array}$ & $\begin{array}{l}\text { CI 95\% } \\
\text { lower }\end{array}$ & $\begin{array}{l}\text { CI 95\% } \\
\text { upper }\end{array}$ & $t$ value & $d f$ & $p$ value \\
\hline PAS $1^{\text {st }}-$ PAS $2^{\text {nd }}$ & -0.0546 & 0.0214 & -0.1022 & -0.0069 & -2.551 & 10 & 0.029 \\
\hline $\mathrm{ACT} 1^{\text {st }}-\mathrm{ACT} 2^{\text {nd }}$ & -0.0318 & 0.0172 & -0.0700 & 0.0064 & -1.855 & 10 & 0.093 \\
\hline LFES $1^{\text {st }}-\operatorname{LFES} 2^{\text {nd }}$ & -0.0836 & 0.0316 & -0.1541 & -0.0132 & -2.644 & 10 & 0.025 \\
\hline
\end{tabular}

PAS - passive recovery, ACT - active recovery, LFES - low-frequency electrical stimulation, Dif - difference between the sprint time in the $1^{\text {st }}$ and the $2^{\text {nd }}$ RSA test, $C I$ - confidence interval, $d f$ - degrees of freedom

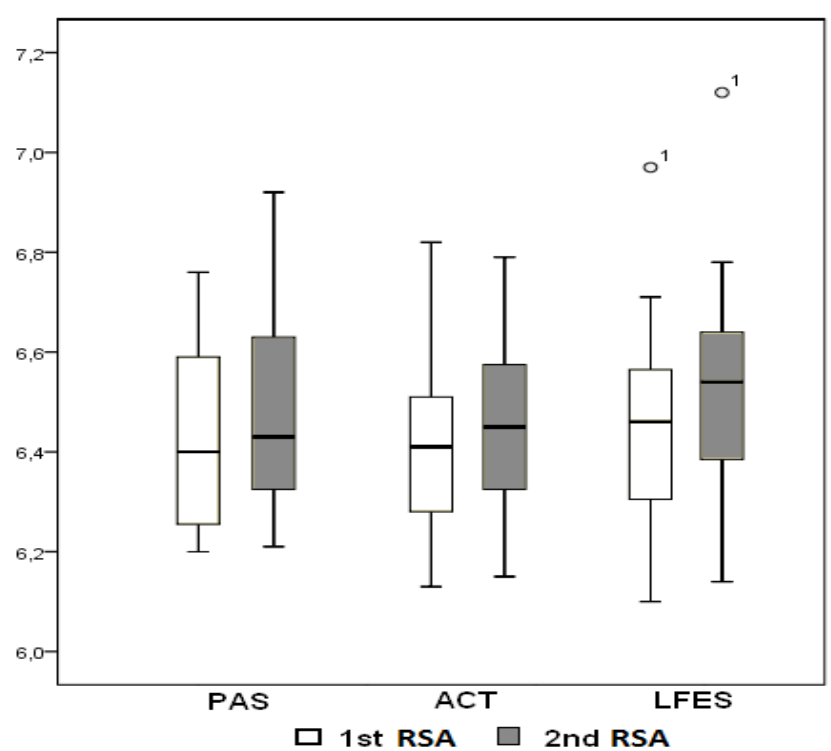

Figure 3. Box plot with medians (horizontal lines inside boxes), quartiles (upper and lower bounds of boxes), and outliers (circles) in the RSA (repeated-sprint ability) test performed before ( $1^{\text {st }}$ RSA test $)$ and after $\left(2^{\text {nd }}\right.$ RSA test) the recovery period for the passive (PAS) and active (ACT) recovery and low-frequency electrical stimulation (LFES) groups

after the PAS, ACT, and LFES recovery modalities can be seen in Figure 3.

\section{DISCUSSION}

Our findings show that ACT recovery has a better effect on repeated-sprint performance than PAS recovery or LFES. It is in accordance with several studies where ACT recovery better influenced performance or lactate removal than PAS recovery in different types of exercise [1-11].

Fatigue during repeated-sprint performance is often associated with accumulation of metabolic by-products [18]. As an attempt to assist in removal of metabolic by-products and accelerate the return to homeostasis, $\mathrm{ACT}$ recovery is generally recommended. It has been shown that increased blood flow induced by ACT recovery accelerates metabolite elimination [19-21]. During PAS recovery in a sitting position, there is minimal muscle activity. In comparison with ACT recovery, the muscle and core temperature decreases [22-24], which may induce impaired performance. For example, decline in high-intensity actions (sprinting, jumping, and dynamic strength) was observed [22, 24, 25]. PAS recovery has also been associated with muscle stiffness and blood flow stagnation [26, 27]. Recently, LFES has been investigated as an alternative to ACT recovery [12]. The rationale for using LFES is to increase blood flow in the muscles and speed up the elimination of metabolites. Bieuzen et al. [13] observed that both ACT recovery and LFES accelerated the return to initial $\mathrm{pH}$ values, as well as blood lactate and bicarbonate concentrations compared with PAS recovery.

There is scarce research evaluating the influence of recovery modalities on run-based repeated-sprint performance separated by a short-term recovery period such as half-time in soccer match. Bieuzen et al. [13] evaluated the effect of different recovery modalities on performance in YYIR2 tests separated by a 15-min recovery period. On the basis of the results presented in their study, both LFES and ACT recovery methods could accelerate recovery during this short-term recovery period. However, the YYIR2 test examines the ability to perform repeated high-intensity exercise with an almost maximum aerobic energy production and a high rate of anaerobic energy turnover [28]. In comparison with Bieuzen et al. [13], we used a more anaerobic related test, which examines the ability to perform repeated sprints with a change of direction. Our study does not confirm an importance of using LFES during a short-term recovery period. We are unable to provide physiological variables to support the observed results, which might be considered a limitation of the study. Future research should attempt to evaluate the effects of different recovery modalities, including LFES, on sprint performance during the match in professional soccer players. 


\section{CONCLUSIONS}

Mean sprint time in the RSA test in amateur soccer players significantly increased after PAS recovery and LFES, whereas its values did not change significantly after ACT recovery. However, small effect sizes indicate that the changes in mean sprint time after these 3 short-term (15-min) recovery periods are not practically significant. In addition, mean sprint time did not differ significantly between groups that underwent different recovery modalities. Taking into account no significant between-group differences in mean sprint time in the RSA test after the 3 recovery modalities applied, one can consider any of them superior.

\section{Acknowledgements}

The work was supported by the Scientific Grant Agency of the Ministry of Education, Science, Research and Sport of the Slovak Republic and the Slovak Academy of Sciences (No. 1/0824/17).

\section{Disclosure statement}

No author has any financial interest or received any financial benefit from this research.

\section{Conflict of interest}

Authors state no conflict of interest.

\section{References}

1. Signorile JF, Ingalls C, Tremblay LM. The effects of active and passive recovery on short-term, high intensity power output. Can J Appl Physiol. 1993;18(1):31-42; doi: 10.1139/h93-004.

2. Thiriet P, Gozal D, Wouassi D, Oumarou T, Gelas H, Lacour JR. The effect of various recovery modalities on subsequent performance, in consecutive supramaximal exercise. J Sports Med Phys Fitness. 1993;33(2):118129.

3. Ahmaidi S, Granier P, Taoutaou Z, Mercier J, Dubouchaud H, Prefaut $C$. Effects of active recovery on plasma lactate and anaerobic power following repeated intensive exercise. Med Sci Sports Exerc. 1996;28(4):450456; doi: 10.1097/00005768-199604000-00009.

4. Bogdanis GC, Nevill ME, Lakomy HK, Graham CM, Louis G. Effects of active recovery on power output during repeated maximal sprint cycling. Eur J Appl Physiol Occup Physiol. 1996;74(5):461-469; doi: 10.1007/ BF02337727.

5. Monedero J, Donne B. Effect of recovery interventions on lactate removal and subsequent performance. Int J Sports Med. 2000;21(8):593-597; doi: 10.1055/s-2000-8488.

6. Connolly DA, Brennan KM, Lauzon CD. Effects of active versus passive recovery on power output during repeated bouts of short term, high intensity exercise. J Sports Sci Med. 2003;2(2):47-51.

7. Spierer DK, Goldsmith R, Baran DA, Hryniewicz K, Katz SD. Effects of active vs. passive recovery on work performed during serial supramaximal exercise tests. Int J Sports Med. 2004;25(2):109-114; doi: 10.1055/s2004-819954.

8. Mika A, Mika P, Fernhall B, Unnithan VB. Comparison of recovery strategies on muscle performance after fatiguing exercise. Am J Phys Med Rehabil. 2007;86(6): 474-481; doi: 10.1097/PHM.0b013e31805b7c79.

9. Heyman E, De Geus B, Mertens I, Meeusen R. Effects of four recovery methods on repeated maximal rock climbing performance. Med Sci Sports Exerc. 2009;41(6): 1303-1310; doi: 10.1249/MSS.0b013e318195107d.

10. White GE, Wells GD. The effect of on-hill active recovery performed between runs on blood lactate concentration and fatigue in alpine ski racers. J Strength Cond Res. 2015;29(3):800-806; doi: 10.1519/JSC.0000000 000000677.

11. Nalbandian HM, Radak Z, Takeda M. Active recovery between interval bouts reduces blood lactate while improving subsequent exercise performance in trained men. Sports. 2017;5(2):40; doi: 10.3390/sports5020040.

12. Bieuzen F, Pournot H, Roulland R, Hausswirth C. Recovery after high-intensity intermittent exercise in elite soccer players using VEINOPLUS sport technology for blood-flow stimulation. J Athl Train. 2012;47(5):498506; doi: 10.4085/1062-6050-47.4.02.

13. Bieuzen F, Borne R, Toussaint JF, Hausswirth C. Positive effect of specific low-frequency electrical stimulation during short-term recovery on subsequent high-intensity exercise. Appl Physiol Nutr Metab. 2014;39(2): 202-210; doi: 10.1139/apnm-2013-0185.

14. Borne R, Hausswirth C, Costello JT, Bieuzen F. Lowfrequency electrical stimulation combined with a cooling vest improves recovery of elite kayakers following a simulated $1000-\mathrm{m}$ race in a hot environment. Scand J Med Sci Sports. 2015;25 Suppl 1:219-228; doi: 10.1111/sms.12392.

15. Gregson W, Drust B, Atkinson G, Salvo VD. Match-tomatch variability of high-speed activities in premier league soccer. Int J Sports Med. 2010;31(4):237-242; doi: 10.1055/s-0030-1247546.

16. Bangsbo J, Mohr M. Fitness testing in football. Espergærde: Bangsbosport; 2011.

17. Cohen J. Statistical power analysis for the behavioral sciences, $2^{\text {nd }}$ ed. Hillsdale: Lawrence Erlbaum Associates; 1988.

18. Girard O, Mendez-Villanueva A, Bishop D. Repeatedsprint ability - part I: factors contributing to fatigue. Sports Med. 2011;41(8):673-694; doi: 10.2165/11590550000000000-00000.

19. Yoshida T, Watari H, Tagawa K. Effects of active and passive recoveries on splitting of the inorganic phosphate peak determined by 31P-nuclear magnetic resonance spectroscopy. NMR Biomed. 1996;9(1):13-19; doi: 


\section{HUMAN MOVEMENT}

J. Pecho, L. Šiška, A. Ščibrány, E. Zemková, Recovery and repeated-sprint performance

10.1002/(SICI)1099-1492(199602)9:1<13::AIDNBM394>3.0.CO;2-9.

20. Fairchild TJ, Armstrong AA, Rao A, Liu H, Lawrence $\mathrm{S}$, Fournier PA. Glycogen synthesis in muscle fibers during active recovery from intense exercise. Med Sci Sports Exerc. 2003;35(4):595-602; doi: 10.1249/01. MSS.0000058436.46584.8E.

21. Neric FB, Beam WC, Brown LE, Wiersma LD. Comparison of swim recovery and muscle stimulation on lactate removal after sprint swimming. J Strength Cond Res. 2009;23(9):2560-2567; doi: 10.1519/JSC.0b013e3181 bc1b7a.

22. Mohr M, Krustrup P, Nybo L, Nielsen JJ, Bangsbo J. Muscle temperature and sprint performance during soccer matches - beneficial effect of re-warm-up at halftime. Scand J Med Sci Sports. 2004;14(3):156-162; doi: 10.1111/j.1600-0838.2004.00349.x.

23. Lovell RJ, Kirke I, Siegler J, McNaughton LR, Greig MP. Soccer half-time strategy influences thermoregulation and endurance performance. J Sports Med Phys Fitness. 2007;47(3):263-269.

24. Lovell R, Midgley A, Barrett S, Carter D, Small K. Effects of different half-time strategies on second half soccer-specific speed, power and dynamic strength. Scand J Med Sci Sports. 2013;23(1):105-113; doi: 10.1111/ j.1600-0838.2011.01353.x.

25. Edholm P, Krustrup P, Randers MB. Half-time re-warm up increases performance capacity in male elite soccer players. Scand J Med Sci Sports. 2015;25(1):e40-e49; doi: 10.1111/sms.12236.

26. Lane KN, Wenger HA. Effect of selected recovery conditions on performance of repeated bouts of intermittent cycling separated by 24 hours. J Strength Cond Res. 2004;18(4):855-860; doi: 10.1519/14183.1.

27. Brown J, Glaister M. The interactive effects of recovery mode and duration on subsequent repeated sprint performance. J Strength Cond Res. 2014;28(3):651-660; doi: 10.1519/JSC.0b013e3182a1fe28.

28. Krustrup P, Mohr M, Nybo L, Jensen JM, Nielsen JJ, Bangsbo J. The Yo-Yo IR2 test: physiological response, reliability, and application to elite soccer. Med Sci Sports Exerc. 2006;38(9):1666-1673; doi: 10.1249/01.mss. 0000227538.20799 .08 . 